\title{
Synthesis of model predictive controller for an identified model of MIMO process
}

\author{
P Chenchu Saibabu, Hitesh Sai, Saksham Yadav, C. R Srinivasan \\ Department of Instrumentation and Control Engineering, Manipal Institute of Technology, \\ Manipal Academy of Higher Education, India
}

\begin{abstract}
Article Info
Article history:

Received Mar 21, 2019

Revised Jul 7, 2019

Accepted Jul 21, 2019

Keywords:

Auto regressive exogenous (ARX)

Model predictive controller

(MPC)

Output error $(\mathrm{OE})$

ABSTRACT

Model Predictive Controller (MPC) technology has been researched and developed to meet varied demands of need to control industrial power plants and petroleum refineries. This development has paved the way for the MPC technology too many other fields like automotive, aerospace, food processing industries in this paper, primary importance has been paid to the development of a MPC for an identified model of Multiple Input and Multiple Output process. In this paper, a Four Tank System has been considered for generation of input-output data. This data i.e. generated input output data is used for the estimation of two polynomial model, name ARX model (Autoregressive exogenous) model and OE (Output Error) model. With each of model output generated, the Fit-Rates of models are compared to find out most efficient model. The model equations are now considered as plant for developing a Model Predictive Controller (MPC). Two sets of results are obtained after the development of MPC and tested. One is without noise and one is with noise. Both sets of results were a success as the output signals traces step input signals after some steady oscillations in real time with in a very short period of time which indicated a good response time. The MPC developed can be applied to any polynomial model with a good Fit-Rate, it predicts and control the process variables automatically.
\end{abstract}

Copyright $@ 2020$ Institute of Advanced Engineering and Science. All rights reserved.

\section{Corresponding Author:}

C R Srinivasan,

Department of Instrumentation and Control Engineering,

Manipal Institute of Technology,

Udupi - Karkala Rd, Eshwar Nagar, Manipal, Karnataka 576104, India.

Email: cr.srinivasan@manipal.edu

\section{INTRODUCTION}

Model identification of a single input and single output system is obtained by minimizing the output error of a closed loop model using constraint optimization. The optimization program is implemented by using FOMCON tool in Matlab [1]. A systematic procedure was derived for handling stationary random problems with multiple inputs and multiple outputs where only auto-spectra are known. This method can also be applied to nonstationary random inputs and deterministic sine and transient problems [2]. Accurate models were derived from the both physical and experimental data and decentralized control was demonstrated on the process. The main purpose was to provide connection between the abstract control theory and the real world. The quadruple-tank process well suited to illustrate performance limitations in multivariable control design caused by right half plane zeros [3]. A mathematically clean formulation of MPC emerged which allowed many researchers to address problems like feasibility stability, performance in a rigorous manner. In nonlinear area variety of issues remained which are technically complex but have potentially significant practical implications for stability and performance and the computational complexity necessary to achieve them. Simulation results of continuous stirred tank heater (CSTR) open loop and closed loop are generated by using Simulink implementations Matlab [4]. MPC has the ability to anticipate future events and can take 
control accordingly. A process model is used to predict the current values of the output variables. The residuals the differences between the actual and the predicted outputs, serve as the feedback signal to a prediction block The predictions are used in two types of MPC calculations that are performed at each sampling instant: set point calculations and the control calculations. The coordination of the control and the set-point calculations is a unique feature of MPC [5] Optimization plays a significant role in designing process of MPC. FARX model of thermal dynamics of buildings is identified by using least square parameter estimation method and Compared the FARX model with the integer order ARX model [6-8]. Identified FARX model is validated by using IESVE software [6]. MPC is proposed to design the energy management system for providing reliable and optimized production of different sources of microgrid [9]. The offline MPC controller based on MPP method was offered for secondary loop to allow motor current to imitate the reference signal from the primary controller. Optimization problem in the MPC controller was altered by incorporating a Laguerre Model approach to decrease the number of decision variables [10].

The detailed above discussion is a stimulus to our present work. Modelling and controlling of multivariable systems is very tedious because they are highly interactive and complex [11]. Often complex models are beneficial for the analysis of system behavior whereas simple models are generally used for design of feedback controllers [12]. Design of controller system for any process to enhance the cost effective modelling and controlling is a difficult task [13]. The entire paper has been divided into three main parts namely, Data Generation [14], System Identification and Model Predictive Control. Basically, data generation refers to process of generating test data [15] for purpose of estimation and testing activities. The data needs to be generated in adherence to the set up test environment and should be in synchronization with developed test cases to fulfil requirement of testing model. Finally data is generated manually by considering the plant equations of Quadruple Tank System. System identification uses the input and output signals that are measured from a system to estimate the values of adjustable parameters in a given model structure. Model Predictive Control, advanced method of process control that has been in use in the process industries in chemical plants and oil refineries. They rely on dynamic model of the process, most often many linear empirical models obtained by system identification.

\section{RESEARCH METHOD}

In this section, data generation from quadruple tank system is generated using System Identification Tool Box and some brief concepts of Model Predictive Controller(MPC) are discussed.

\subsection{Physical Model}

Quadruple tank consists of two inputs namely pump voltage v1, pump voltage v2 and two outputs namely tank1 height, tank 2 height. Schematic diagram of quadruple tank process as shown in Figure 1.

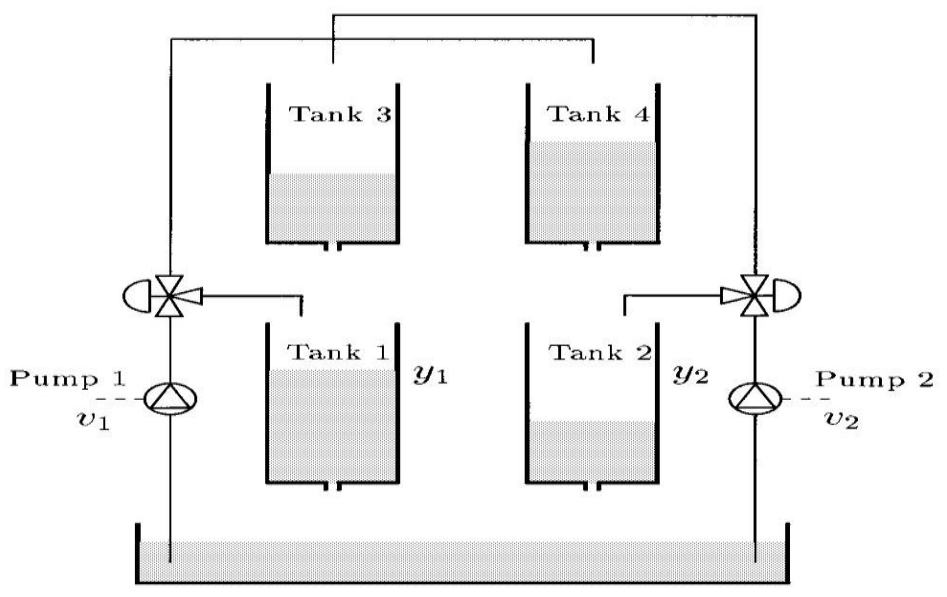

Figure 1. Schematic diagram of quadruple tank process [3]

The quadruple tank process is represented by following equations [3]:

$$
\frac{\mathrm{dh} 1}{d t}=-\frac{a 1}{A 1} \sqrt{2 g h 1}+\frac{\mathrm{a} 3}{A 1} \sqrt{2 g h 3}+\frac{\gamma 1 \mathrm{k} 1}{A 1} v_{1}
$$




$$
\begin{aligned}
& \frac{\mathrm{dh} 2}{d t}=-\frac{a 2}{A 2} \sqrt{2 g h 2}+\frac{\mathrm{a} 4}{A 2} \sqrt{2 g h 4}+\frac{\gamma 2 \mathrm{k} 2}{A 2} \mathrm{v}_{2} \\
& \frac{\mathrm{dh} 3}{d t}=-\frac{a 3}{A 3} \sqrt{2 g h 3}+\frac{(1-\gamma 2) \mathrm{k} 2}{A 3} \mathrm{v}_{2} \\
& \frac{\mathrm{dh} 4}{d t}=-\frac{a 4}{A 4} \sqrt{2 g h 4}+\frac{(1-\gamma 1) \mathrm{k} 1}{A 4} \mathrm{v}_{1}
\end{aligned}
$$

Where $\mathrm{h}_{\mathrm{i}}=$ level of tank $\mathrm{i}, \mathrm{A}_{\mathrm{i}}=$ cross section of tank $\mathrm{i}, \mathrm{a}_{\mathrm{i}}=$ cross section of outlet pipe.

The voltage applied to Pump is $\mathrm{v}_{\mathrm{i}}$ and its flow is $\mathrm{k}_{\mathrm{i}} \mathrm{v}_{\mathrm{i}}$. The parameters $\gamma_{1}, \gamma_{2} \in(0,1)$ are determined from how the valves are set prior to an experiment. The flow to Tank 1 is $\gamma 1 \mathrm{k} 1 \mathrm{v} 1$ and the flow to tank4 is (1- $\gamma 1) \mathrm{k} 1 \mathrm{v} 1$ and similarly for Tanks 2 and 3. The acceleration of gravity is denoted by $\mathrm{g}$ and the measured level signals are $\mathrm{k}_{\mathrm{c}} \mathrm{h}_{1}$ and $\mathrm{k}_{\mathrm{c}} \mathrm{h}_{2}$. Out of all parameters, two inputs $(\mathrm{v} 1, \mathrm{v} 2)$ and two outputs $(\mathrm{h} 1, \mathrm{~h} 2)$ are considered and plotted. During the data generation white noise unmeasured disturbance signals are added to the two outputs of the process. These unmeasured disturbance dynamics are assumed as the stochastic process of following governing models [16-17]

$$
\begin{aligned}
& C(k)=\frac{0.04}{1-0.96 z^{-1}} N_{1}(k) \\
& C(k)=\frac{0.02}{1-0.97 z^{-1}} N_{2}(k)
\end{aligned}
$$

Training data is a dataset used to fit the parameter. Validation set can be regarded as a part of the training set because it is used to build model. It is also used for parameter selection and to avoid over-fitting. Out of 1000 samples 750 samples are taken for training data and 250 samples are taken for validation data.

\section{Specifications:}

System model parameters and initial conditions of quadruple tank assumed are as follows:

Model parameters of quadruple tank as shown in Table 1.

Table 1. Model Parameters of Quadruple Tank [3]

\begin{tabular}{cc}
\hline Parameters & Values \\
\hline $\mathrm{A} 1$ & $28 \mathrm{~cm}^{2}$ \\
$\mathrm{~A} 2$ & $32 \mathrm{~cm}^{2}$ \\
$\mathrm{~A} 3$ & $28 \mathrm{~cm}^{2}$ \\
$\mathrm{~A} 4$ & $32 \mathrm{~cm}^{2}$ \\
$\mathrm{a} 1$ & $0.07 \mathrm{~cm}^{2}$ \\
$\mathrm{a} 2$ & $0.057 \mathrm{~cm}^{2}$ \\
$\mathrm{a} 3$ & $0.07 \mathrm{~cm}^{2}$ \\
$\mathrm{a} 4$ & $0.057 \mathrm{~cm}^{2}$ \\
$\mathrm{k}_{\mathrm{c}}$ & $0.5 \mathrm{~V} / \mathrm{cm}^{2}$ \\
$\mathrm{~g}$ & $981 \mathrm{~cm} / \mathrm{sec}^{2}$ \\
$\mathrm{k} 1$ & $3.33 \mathrm{~V} / \mathrm{cm}$ \\
$\mathrm{k} 2$ & $3.35 \mathrm{~V} / \mathrm{cm}$ \\
$\gamma 1$ & 0.7 \\
$\gamma 2$ & 0.6 \\
\hline
\end{tabular}

\subsection{System Identification}

\subsubsection{Output Error Model (OE model): Structure of Output Error Model is Given by Following} Equations [18-20]:

$\mathrm{y}(\mathrm{k})=\mathrm{B}(\mathrm{q}-1) / \mathrm{F}(\mathrm{q}-1) \mathrm{u}(\mathrm{k})+\mathrm{e}(\mathrm{k})$

i.e., non-linear optimization problem for parameter estimation of output error defined.

$\Psi(\hat{v}(1) \hat{v}(\mathrm{k}))=\sum_{i=1}^{N}[\hat{v}(\mathrm{k})]^{2}$

Where $\hat{v}(\mathrm{k})=\mathrm{y}(\mathrm{k})-\hat{\mathrm{x}}(\mathrm{k})$

$\hat{\mathrm{x}}(\mathrm{k})=-\mathrm{a}_{1} \hat{\mathrm{x}}(\mathrm{k}-1)-\mathrm{a}_{2} \hat{\mathrm{x}}(\mathrm{k}-2)+\mathrm{b}_{1} \hat{\mathrm{x}}(\mathrm{k}-2)+\mathrm{b}_{2} \hat{\mathrm{x}}(\mathrm{k}-3)$ 
2.2.2 Auto Regressive Exogenous Model (ARX model): The Equations for ARX [18, 21, 22] Model Given by Following:

$$
\begin{aligned}
& \mathrm{y}(\mathrm{k})=\mathrm{B}(\mathrm{q}-1) / \mathrm{A}(\mathrm{q}-1) \mathrm{u}(\mathrm{k})+\mathrm{e}(\mathrm{k}) / \mathrm{A}(\mathrm{q}-1) \\
& \hat{\mathrm{e}}=\min _{\mathrm{a} 1, \mathrm{~b} 1, \mathrm{a} 2, \mathrm{~b} 2} \sum_{i=1}^{N}\left(\mathrm{e}^{\hat{n}}(\mathrm{k})\right)^{2}=\Theta_{\min }\left(\mathrm{e}^{\mathrm{T} * \mathrm{e}}\right) \\
& \psi=\mathrm{e}^{\mathrm{T} * \mathrm{e}}=[\mathrm{Y}-\Omega \Theta]^{\mathrm{T} *}[\mathrm{Y}-\Omega \Theta]
\end{aligned}
$$

2.2.3 Model Predictive Controller (MPC): The Conventional Kalman Filter [23] based on MPC Formulation is Developed Starting from Model:

$$
\begin{aligned}
& \mathrm{x}(\mathrm{k}+1)=\Phi \mathrm{x}(\mathrm{k})+\Gamma \mathrm{u}(\mathrm{k})+\mathrm{w}(\mathrm{k}) \\
& \mathrm{y}(\mathrm{k})=\mathrm{C} \mathrm{x}(\mathrm{k})+\mathrm{v}(\mathrm{k}) \\
& \hat{\mathrm{x}}(\mathrm{k}+\mathrm{j}+1 \mid \mathrm{k})=\Phi \hat{\mathrm{x}}(\mathrm{k}+\mathrm{j} \mid \mathrm{k})+\Gamma \mathrm{u}(\mathrm{k}+\mathrm{j} \mid \mathrm{k})+\mathrm{L} \varepsilon(\mathrm{k}+\mathrm{j} \mid \mathrm{k}) \\
& \varepsilon(\mathrm{k}+\mathrm{j}+1 \mid \mathrm{k})=\varepsilon(\mathrm{k}+\mathrm{j} \mid \mathrm{k}) \\
& \hat{\mathrm{y}}(\mathrm{k}+\mathrm{j})=\mathrm{C} \hat{\mathrm{x}}(\mathrm{k}+\mathrm{j} \mid \mathrm{k})+\varepsilon(\mathrm{k}+\mathrm{j} \mid \mathrm{k})
\end{aligned}
$$

For $\mathrm{j}=0,1,2 \ldots \mathrm{p}-1$. Here, $\varepsilon$ belongs to $\mathrm{R}$ behaves as an integrated white noise signal that provides compensation for the unmeasured disturbance/model plant mismatch. The initial value at beginning of horizon, $\varepsilon(\mathrm{k} \mid \mathrm{k})$, is estimated by filtering the innovation sequence $\{\mathrm{e}(\mathrm{k})\}$ through a unity gain robustness filter [24] as follows:

$$
\begin{aligned}
& \mathrm{e}_{\mathrm{f}}(\mathrm{k})=\emptyset_{\mathrm{e}} \mathrm{e}_{\mathrm{f}}(\mathrm{k}-1)+\left[1-\emptyset_{\mathrm{e}}\right] \mathrm{e}(\mathrm{k}) \\
& \varepsilon(\mathrm{k} \mid \mathrm{k})=\mathrm{ef}(\mathrm{k}) \\
& \mathrm{e}(\mathrm{k})=\mathrm{y}(\mathrm{k})-\mathrm{Cx}(\mathrm{k} \mid \mathrm{k}-1) \\
& \hat{\mathrm{x}}(\mathrm{k} \mid \mathrm{k}-1)=\Phi \hat{\mathrm{x}}(\mathrm{k}-1 \mid \mathrm{k}-2)+\Gamma \mathrm{u}(\mathrm{k}-1)+\mathrm{Le}(\mathrm{k}-1)
\end{aligned}
$$

To compare the performances of MPC controllers developed using identified models, the performance index (JMPC) defined as:

$$
\mathrm{J}_{\mathrm{MPC}}=\sum_{k=1}^{N s}[\mathrm{r}(\mathrm{k})-\mathrm{y}(\mathrm{k})]^{\mathrm{T}} \mathrm{W}_{\mathrm{E}}[\mathrm{r}(\mathrm{k})-\mathrm{y}(\mathrm{k})]+\Delta \mathrm{u}(\mathrm{k})^{\mathrm{T}} \mathrm{W}_{\Delta \mathrm{U}} \Delta \mathrm{u}(\mathrm{k})[7,25]
$$

Is used which is based on objective function used in the proposed MPC formulation. In addition, the optimization technique used is integral square of errors (ISE) defined as:

$$
\operatorname{ISE}(\mathrm{yi})=\sum_{k=1}^{N s}[\mathrm{yi}(\mathrm{k})-\operatorname{ri}(\mathrm{k})]^{2}[7]
$$

Where Ns is the length of simulation trail, $r(k)-y(k)$ is an objective function, $\mathrm{W}_{\mathrm{E}}$ is input weight, $\mathrm{W}_{\Delta \mathrm{U}}$ is the output weight.

\section{RESULTS}

\subsection{Data Generation}

In this section generation of stable response for quadruple tank system identification of efficient model among OE model \& ARX model and generation of responses for MPC with and without noise are obtained. Input-output data is generated from MATLAB code of four tank system without noise which is represented in graphical forms as shown in Figure $2 \mathrm{a}$ and $3 \mathrm{~b}$. Initial conditions of outputs such as height of the tank 1 and tank 2 given as $12.75,13.1$ respectively.

Input-output data is generated from MATLAB code of quadruple tank system with noise which is represented in graphical forms as shown in Figure 3a and 4b. Out of 1000 samples 750 samples are taken for training data and 250 samples are taken for validation data as shown in above figure. 

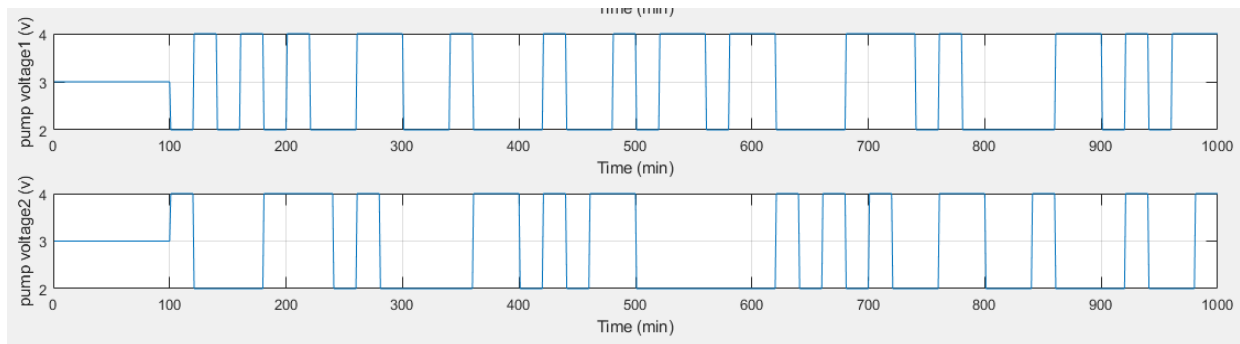

(a)
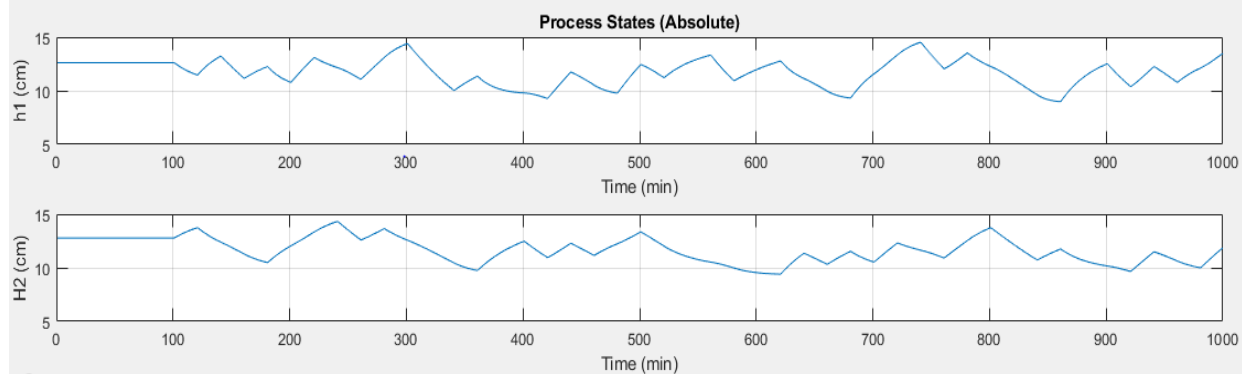

(b)

Figure 2. Input and outputs plots for quadruple tank system without noise

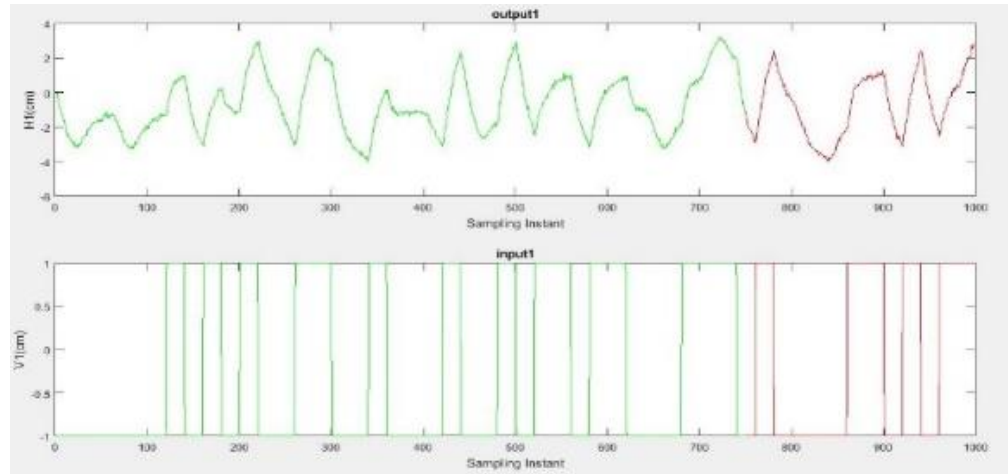

(a)

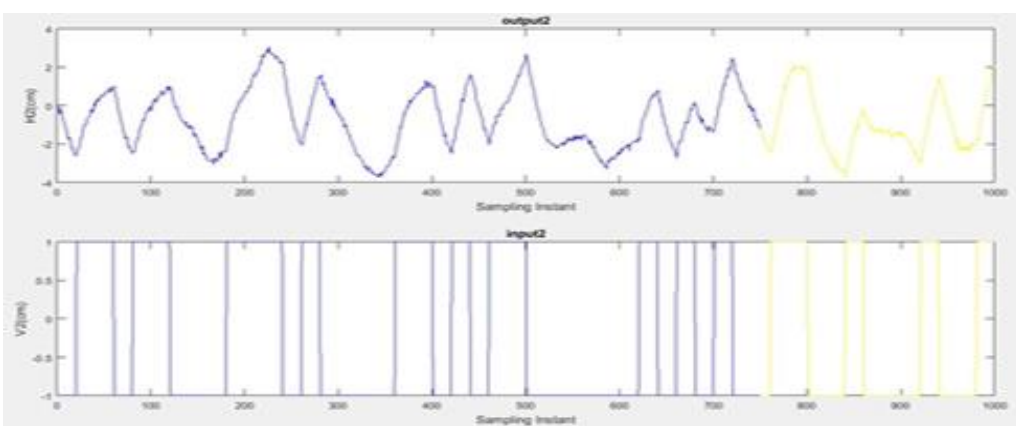

(b)

Figure 3. Input and output plots for quadruple tank system without noise

\subsection{System Identification}

Using data from Figure $2 \mathrm{a}$ and $2 \mathrm{~b}$, two polynomial models are generated namely OE and ARX model as shown in Figure $4 \mathrm{a}$ and $4 \mathrm{~b}$. 


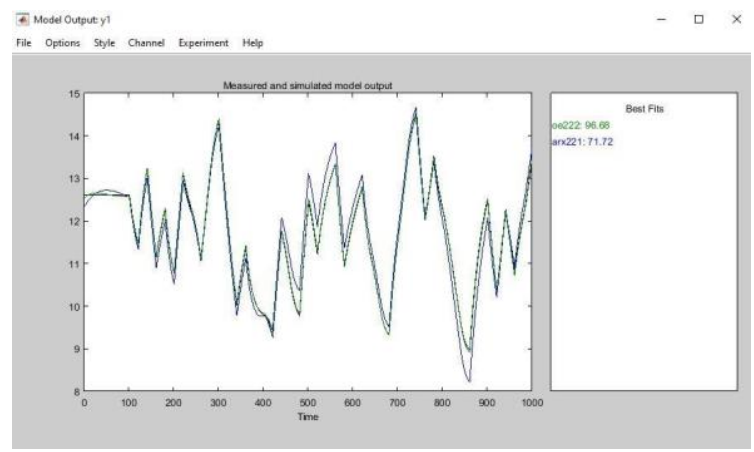

(a)

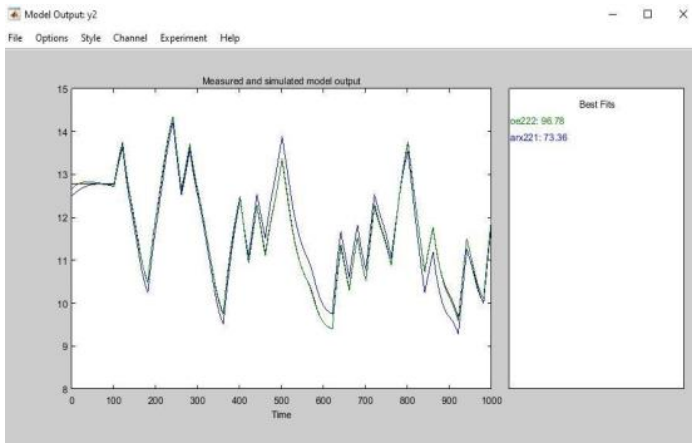

(b)

Figure 4. Fit rates for output y1 and y2 without noise

Model output y1 has fitrates of $96.88,71.72$ for OE \& ARX model and model output y2 has fit rates of 96.78, 73.36 for OE and ARX without noise models. Using data from Figure 4a and 4b. two polynomial models are generated namely ARX and OE model as shown in Figure 5a, 5b, 6a and 6b.

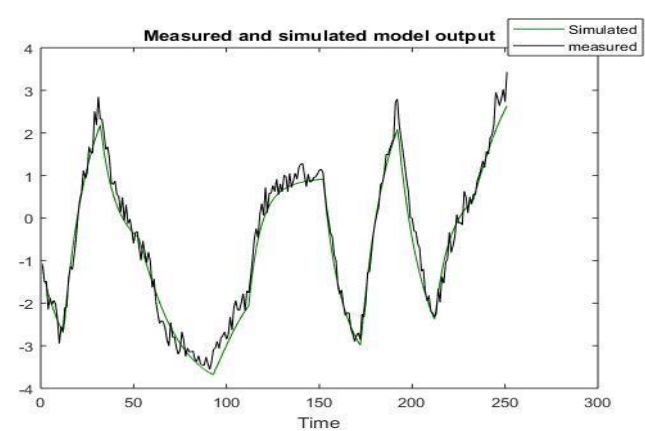

(a)

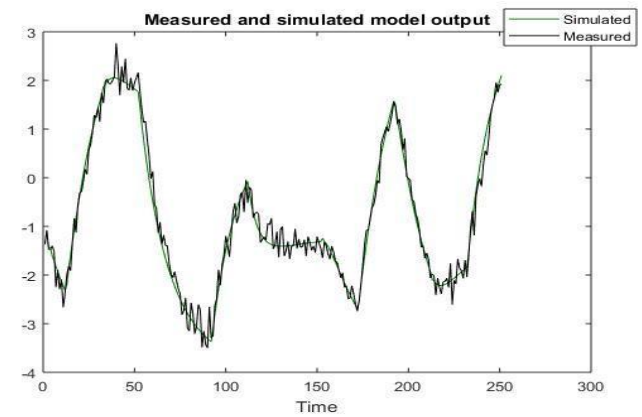

(b)

Figure 5. ARX model output y1 and y2 with noise

Discrete ARX model of four tank system is obtained as

$$
\left[\begin{array}{cc}
\frac{0.19081 z^{-1}+0.1435 z^{-2}}{1-0.4197 z^{-1}-0.409 z^{-2}} & \frac{0.006292 z^{-1}+0.06521 z^{-2}}{-0.05776 z^{-1}-0.0187 z^{-2}} \\
\frac{-0.034 z^{-1}+0.04084 z^{-2}}{1-0.4207 z^{-1}-0.4367 z^{-2}} & \frac{0.4 z^{-1}+0.11 z^{-2}}{-0.0674 z^{-1}-0.00412 z^{-2}}
\end{array}\right]
$$

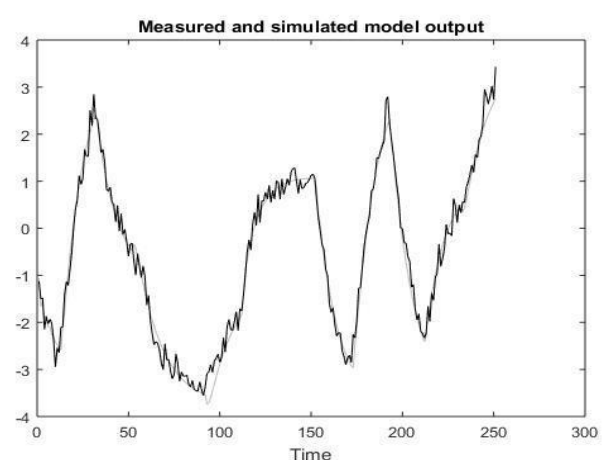

(a)

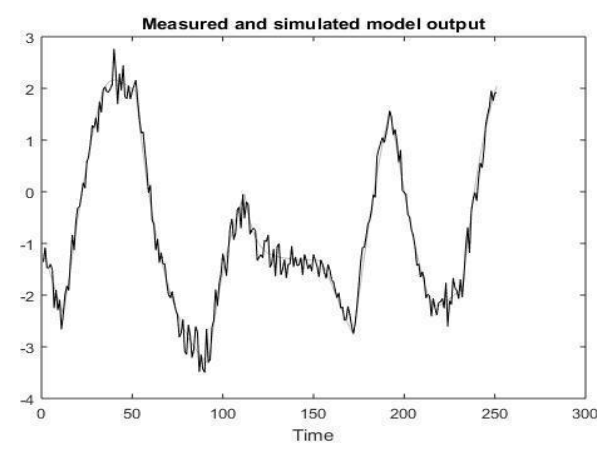

(b)

Figure 6. OE model output y1 and y2 with noise 
Discrete OE model of four tank system is obtained as

$$
\left[\begin{array}{cc}
\frac{0.1081 z^{-1}+0.256 z^{-2}}{1-0.141 z^{-1}-0.707 z^{-2}} & \frac{-0.0817 z^{-1}+0.144 z^{-2}}{1-1.3580 z^{-1}+0.3966 z^{-2}} \\
\frac{0.0017 z^{-1}+0.01047 z^{-2}}{1-1.78 z^{-1}+0.7932 z^{-2}} & \frac{0.1492 z^{-1}+0.1397 z^{-2}}{1-1.88 z^{-1}+0.8857 z^{-2}}
\end{array}\right]
$$

From the above Figure 5, model output yl has fit rates of $86.43,82.49$ and similarly from the Figure 6, model output y2 has fit rates of 85.67, 84.09 for ARX and OE noise models.

\subsection{Closed Loop Response}

Simulating the MPC plant model with Simulink input and output plots are generated for MPC plant without noise as shown in Figure 7 and Figure 8. Prediction and control horizons are considered as 5 and 2 respectively. Simplex optimization technique is used for optimization of MPC parameters.

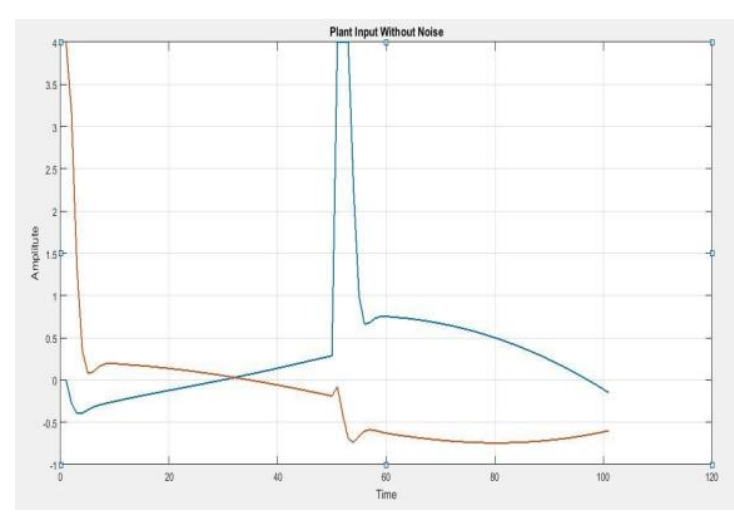

Figure 7. Input plots for MPC plant without noise

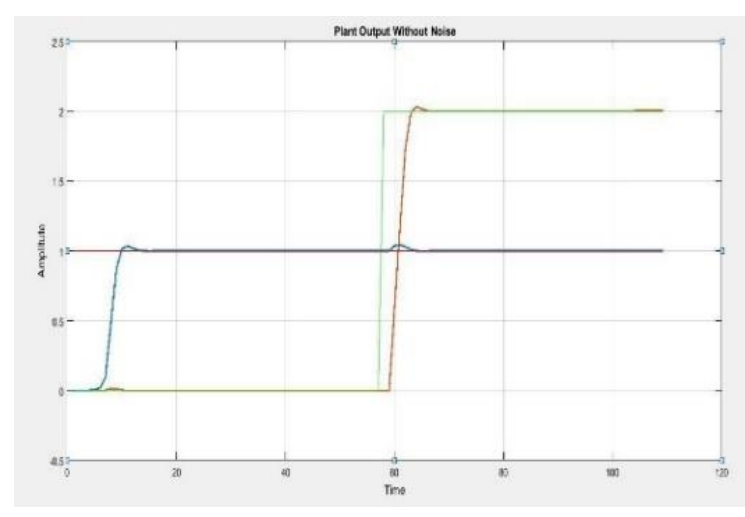

Figure 8. Output plots for MPC plant without noise

From the Figure 8, outputs increase slowly with each step change i.e. outputs track the step inputs and reaches steady state. Simulating the MPC plant model with Simulink input and output plots are generated for MPC plant with noise as shown in Figure 9 and 10. From Figure 10, initially there is an inverse response for each step change and reaches steady state at the end.

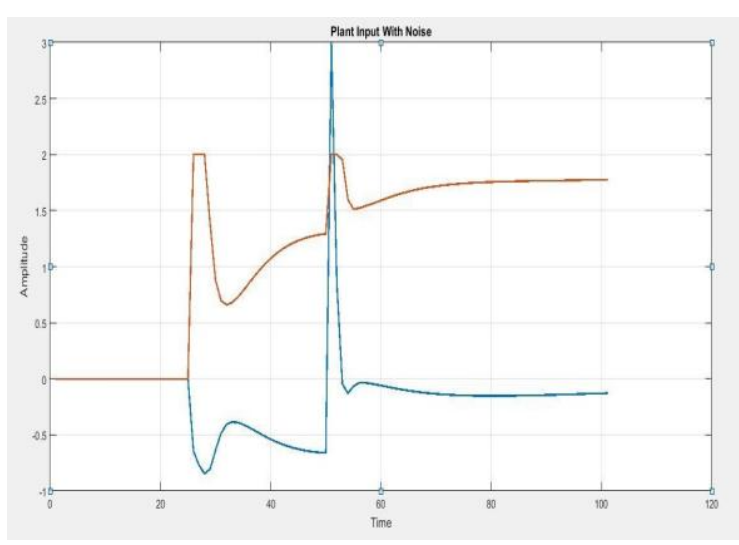

Figure 9. Input plots for MPC plant with noise

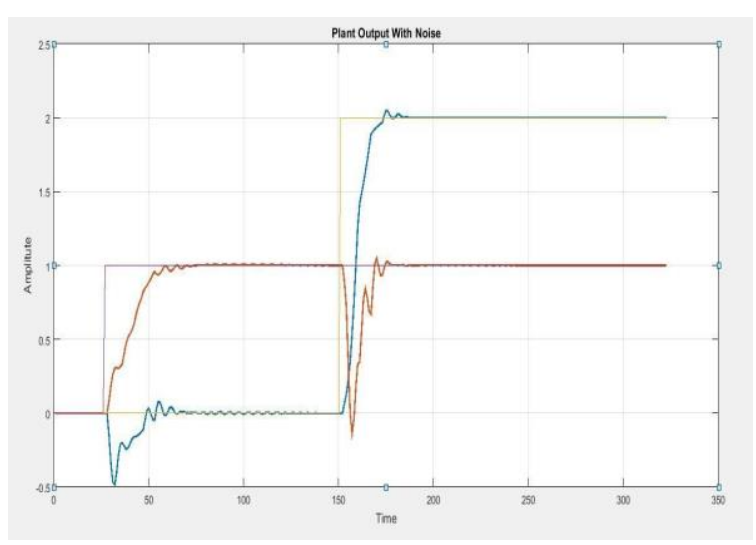

Figure 10. Output plots for MPC plant with noise

\section{CONCLUSIONS}

In this section, primary importance has been paid to the development of a MPC for an identified model of a Multi-Input and Multiple-Output process . A Four Tank System was considered for the generation of input-output data. This data, once generated, used for the estimation of two polynomial models, namely 
ARX (Auto Regressive Exogenous) model and OE (Output-Error) model. With each of model output generated, the Fit-Rates of the models were compared to find out the most efficient model. After choosing the best model, the model equations developed. These model equations were then considered as the plant equations for developing a MPC Two sets of results were obtained after the MPC was developed and tested. One was without noise and other was with noise. Both sets of results were a success as the output signals traced the step input signals after some steady oscillations in real-time within a very short period of time, which indicated a good response time. Quite commonly MPC applications in industries involves dozens of inputs and outputs. The need is to develop multivariable models of such sizes through plant tests puts unprecedented demands on model identification techniques. In most cases, model fitting done using SISO, MISO methods. Because the model for each output is fitted separately in these methods, correlations among different outputs cannot be captured or exploited. Particularly designing a MPC in some applications where some of the controlled variable are either not measured or measured with large delays and must be inferred from secondary process measurements for satisfactory control. Many MPC's that perform well when first commissioned deteriorate over time, some leading to eventual shutdown. In order to sustain benefits of MPC's over long period of time, a mechanism to detect abnormality and dragonize its root cause is needed. The results can be communicated to engineers and can also be used to adapt the control parameters.

\section{REFERENCES}

[1] Aleksei Tepljakov, Eduard Petlenkov and Juri Belikov, "Closed-Loop identification of fractional-order models using FOMCON toolbox for MATLAB," 14th Biennial Baltic Electronic Conference, tallina, Estonia, 2014.

[2] David O Smallwood, "Multiple input multiple-output linear systems extreme inputs outputs," Shock and Vibration 14, ISO Press, 2006.

[3] Karl Henrik Johansson, "The quadruple tank process: A multivariable laboratory process with an adjustable zero," Control Systems Technology, vol. 8, no. 3, 2000.

[4] Nina F Thomhill, Sachin C. Patwardhan, Sirish L. Shah, "A continuous stirred tank heater simulation model with applications," Centre for Process control Engineering, Department of Chemical and Materials Engineering, 2000.

[5] Manfred Morari and Jay H Lee, "Model predictive control past present and future," Computers and Chemical Engineering, vol. 23, 1998.

[6] Lin Chen, Biswajit Basu, and David McCabe, "Fractional order models for system identification of thermal dynamicsof buildings," Energy and Buildings, vol. 133, pp. 381-388, 2016.

[7] Muddu Madakvaru, Anuj Narang and Sachin C. Patwardhan, "Development of ARX models for predictive control using fractional order and orthonormal basis filter parametrization," Systems and Control Engineering and Department of Chemical Engineering, IIT. Bombay, Ind. Eng Chem. Res., 48,8966,89798966, 2009.

[8] Aoun, M., Malti. R Levron, F., \&amp, Oustaloup A, "Synthesis of fractional laguerre basis for system approximation" Automatica, pp. 1640-1648, 2007.

[9] M. Reyasudin Basir Khan , Jagadeesh Pasupuleti , Jabbar Al-Fattah , Mehrdad Tahmasebi, "Energy management system for PV-Battery microgrid based on model predictive control", Indonesian Journal of Electrical Engineering and Computer Science, Vol. 15, No. 1, July 2019, pp. 20-25.

[10] Nguyen Hong Quang, Nguyen Phung, Dao Phuong Na, Nguyen Thanh Binh, "Multi parametric model predictive control based on laguerre model for permanent magnet linear synchronous motors", International Journal of Electrical and Computer Engineering (IJECE) Vol. 9, No. 2, April 2019, pp. 1067-1077.

[11] Mohamed Essahafi, Mustapha Ait Lafkih," Microclimate Control of a Greenhouse by Adaptive Generalized Linear Quadratic Strategy," Indonesian Journal of Electrical Engineering and Computer Science, Vol. 11, No. 1, July 2018, pp. 377 385.

[12] S. Y. Sim , C. K. Chia , W. M. Utomo, H. H. Goh, Y. M. Y. Buswig, A. J. M. S. Lim6, S. L. Kek, A. A. Bohari , C. L. Cham," Enhance Cascaded H-Bridge Multilevel Inverter with Artificial Intelligence Control," Indonesian Journal of Electrical Engineering and Computer Science Vol. 11, No. 1, July 2018, pp. 105 112.

[13] Ramana Pilla , Killari Santukumari , K.B.Madhu Sahu,” Design and Simulation of the Control System for Invertefed Permanent Magnet Synchronous Motor Drive", Indonesian Journal of Electrical Engineering and Computer Science Vol. 12, No. 3, December 2018, pp. 958 967.

[14] Susobhit Sen, Anjan Kumar, C R Shrinivasan, Chenchu Saibabu, "Efficient and Low Cost Flow Measurement Using Bend Sensor Flowmeter", International Journal of Electronic and Electrical Engineering. ISSN 0974-2174 Volume 7, Number 8 (2014), pp. 879-885.

[15] Thulfiqar H. Mandeel, Muhammad Imran Ahmad, Said Amirul Anwar," A multi-instance multi-sample palmprint identification system," Indonesian Journal of Electrical Engineering and Computer Science Vol. 13, No. 2, February 2019, pp. 825 830.

[16] M. Muddu, A. Narang, and S. C.Patwardhan, "Reparametrized ARX models for predictive control of staged and packed bed distillation columns," Control Engineering Practice, vol. 18, pp. 114-130, 2010.

[17] N. F. Thornhill, S. C. Patwardhan, and S. L. Shah, "A continuous stirred tank heater simulation model with applications," Journal of Process Control, vol. 18, pp. 347-360, 2008.

[18] Maruja S Narasimhan. S \&amp, Patwardhan S. C, "Unknown input modeling and robust fault diagnosis using black box," Journal of Process Control, pp. 25-37, 2009. 
[19] Heuberger, P. S.C Van Den Hof, P. M.J.,\&amp Walhberg, B, "Modelling and identification with rational orthogonal basis functions," London, Springer, 2005

[20] F. Ferranti and Y. Rolain, "A local identification method for linear parameter-varying systems based on interpolation of state-space matrices and least-squares approximation," Mechanical Systems and Signal Processing, vol. 82, pp. 478-489, 2016.

[21] David O Smallwood "Multiple input multiple-output linear systems extreme inputs outputs," Shock and Vibration 14, ISO Press, 2006.

[22] R. Toth, "Modeling and identification of linear parameter varying systems," New York, Springer, 2010.

[23] Muske K R\&amp Badewell, T. A., "Disturbance modeling for offset free linear model predictive control," Journal of Process Control, pp. 617-632, 2002.

[24] S. J. Qin and T. A. Badgwell, "A survey of industrial model predictive control technology," Control Eng. Practice, vol. 11, pp. 733-764, 2003.

[25] J. A. Rossiter, "Model predictive control for beginners by anthony rossiter," 2016. 